\title{
Derivation of a risk scale and quantification of risk factors for serious adverse events in adult emergency department syncope patients
}

\author{
Venkatesh Thiruganasambandamoorthy, MBBS, MSc ${ }^{*{ }^{\dagger}}$; George A. Wells, $\mathrm{PhD}^{\ddagger}$; \\ Erik P. Hess, MD, MSc ${ }^{\S}$; Ekaterina Turko, MD*; Jeffrey J. Perry, MD, MSc ${ }^{\star \ddagger}$; Ian G. Stiell, MD, MSc ${ }^{* \ddagger}$
}

\section{ABSTRACT}

Background: Determining the appropriate disposition of emergency department (ED) syncope patients is challenging. Previously developed decision tools have poor diagnostic test characteristics and methodological flaws in their derivation that preclude their use. We sought to develop a scale to risk-stratify adult ED syncope patients at risk for serious adverse events (SAEs) within 30 days.

Methods: We conducted a medical record review to include syncope patients age $\geq 16$ years and excluded patients with ongoing altered mental status, alcohol or illicit drug use, seizure, head injury leading to loss of consciousness, or severe trauma requiring admission. We collected 105 predictor variables (demographics, event characteristics, comorbidities, medications, vital signs, clinical examination findings, emergency medical services and ED electrocardiogram/monitor characteristics, investigations, and disposition variables) and information on the occurrence of predefined SAEs. Univariate and multiple logistic regression analyses were performed.

Results: Among 505 enrolled patient visits, 49 (9.7\%) suffered an SAE. Predictors of SAE and their resulting point scores were as follows: age $\geq 75$ years (1), shortness of breath (2), lowest ED systolic blood pressure $<80 \mathrm{~mm} \mathrm{Hg}(2)$, Ottawa Electrocardiographic Criteria present (2), and blood urea nitrogen $>15 \mathrm{mmol} / \mathrm{L}$ (3). The final score calculated by addition of the individual scores for each variable (range 0 10) was found to accurately stratify patients into low risk (score $<1,0 \%$ SAE risk), moderate risk (score 1, 3.7\% SAE risk), or high risk (score $>1, \geq 10 \% \mathrm{SAE}$ risk).

Conclusion: We derived a risk scale that accurately predicts SAEs within 30 days in ED syncope patients. If validated, this will be a potentially useful clinical decision tool for emergency physicians, may allow judicious use of health care resources, and may improve patient care and safety.

\section{RÉSUMÉ}

Contexte: II n'est pas facile de décider correctement du sort des patients examinés au service des urgences (SU) pour des syncopes. II existe des outils d'aide à la décision, mais leurs piètres caractéristiques quant à la valeur diagnostique et des vices de méthodologie empêchent leur utilisation dans la conception de nouveaux instruments. Aussi avons-nous tenté d'élaborer une échelle d'évaluation du risque d'événements indésirables graves (EIG) au bout de 30 jours, chez les patients examinés au SU pour des syncopes.

Méthode: L'étude consistait en un examen des dossiers médicaux de patients âgés de 16 ans et plus et tombant en syncope, à l'exclusion de ceux atteints d'un problème de santé mentale continu, faisant usage d'alcool ou de drogues illicites, souffrant de crises épileptiques, ayant subi un trauma crânien qui a provoqué une perte de connaissance ou un trauma suffisamment grave pour nécessiter I'hospitalisation. Ont été recueillis des données sur 105 variables prévisionnelles (données démographiques, caractéristiques des événements, maladies concomitantes, médicaments, signes vitaux, résultats des examens cliniques, services médicaux d'urgence et caractéristiques de l'électrocardiographie ou du monitorage au SU, exploration et variables relatives au sort des patients) ainsi que des renseignements sur la survenue d'EIG prédéterminés. Des analyses de régression logistiques uni- et multidimensionnelles ont été réalisées par la suite.

From the *Department of Emergency Medicine, University of Ottawa, Ottawa, ON; †The Ottawa Hospital Research Institute, The Ottawa Hospital, Ottawa, ON; łDepartment of Epidemiology and Community Medicine, University of Ottawa, Ottawa, ON; §Division of Emergency Medicine Research, Department of Emergency Medicine, Mayo Clinic College of Medicine, Rochester, MN.

Presented at the Society for Academic Emergency Medicine Annual Meeting 2009, New Orleans, LA, and the Canadian Association of Emergency Physicians' Annual Scientific Assembly 2009, Calgary, AB.

Correspondence to: Dr. Venkatesh Thiruganasambandamoorthy, Ottawa Health Research Institute, Clinical Epidemiology Unit, The Ottawa Hospital, Civic Campus, 1053 Carling Avenue, 6th Floor, Room F655, Ottawa, ON K1Y 4E9; vthirug@ohri.ca.

This article has been peer reviewed. 
Résultats: Sur 505 patients participants, 49 (9.7\%) ont subi un EIG. Les facteurs prévisionnels d'EIG et la notation en points qui en a résulté se sont établis comme suit: âge $\geq 75$ ans, 1; essoufflement, 2; pression systolique la plus basse enregistrée au SU $<80 \mathrm{~mm} \mathrm{Hg}$, 2; présence des critères électrocardiographiques d'Ottawa, 2; azote uréique du sang $>$ $15 \mathrm{mmol} / \mathrm{L}, 3$. Le résultat final obtenu par l'addition des résultats individuels, enregistrés pour chacune des variables (plage: 0 10) s'est révélé juste et il permet de classer correctement les patients dans les catégories suivantes: risque faible (point $<1$; risque d'EIG $=0 \%$ ), risque modéré (point $=1$; risque $\mathrm{d}^{\prime} \mathrm{EIG}=$ $3.7 \%$ ), et risque élevé (point $>1$; risque $d^{\prime} E I G \geq 10 \%$ ).
Conclusions: Nous avons élaboré une échelle d'évaluation du risque qui permet de prévoir avec justesse la survenue d'EIG, au bout de 30 jours, chez les patients examinés au SU pour des syncopes. Si l'échelle est validée, il s'agira d'un outil d'aide à la décision clinique qui pourra se révéler utile aux urgentologues, qui permettra une utilisation judicieuse des ressources en soins de santé et qui pourra améliorer les soins aux patients, de même que leur sécurité.

Keywords: emergency department, risk scale, serious adverse event, syncope
Syncope is defined as a sudden transient loss of consciousness followed by spontaneous complete recovery. ${ }^{1}$ Syncope is a common emergency department (ED) presentation and accounts for 1 to $3 \%$ of $\mathrm{ED}$ visits and $2 \%$ of hospital admissions from the ED. Among ED syncope patients, 7 to $23 \%$ will suffer a serious adverse event (SAE) within 7 to 30 days of their visit. ${ }^{2-10}$ These include death, arrhythmia, myocardial infarction, diagnosis of serious underlying structural heart disease, or procedural interventions to treat the cause of the syncopal event. . $^{2,3,5-11}$

The decision to perform a diagnostic workup in the ED for patients with syncope or admit them for evaluation is an important consideration given the current crowding of EDs and widespread shortage of hospital beds. ${ }^{12}$ In Canada, $87.7 \%$ of syncope patients are discharged from the ED, $2.7 \%$ of whom suffer an SAE. It has been found that the current ED approach to syncope in Canada fails to predict $30 \%$ of SAEs, including $67 \%$ of deaths that occur after ED disposition. ${ }^{13}$ These findings underscore the need for a clinical decision tool. Several previous attempts have been made to develop tools for predicting short-term SAEs in ED syncope patients. $2,8,10,14,15$ All the instruments arising from these efforts have either not been validated or have performed poorly on external validation. $^{4-6,15}$ Most such instruments, if applied in the Canadian setting, will likely substantially increase admission rates. ${ }^{4}$

In addition, many previous decision instruments have been limited by an imprecise definition of the "abnormal electrocardiogram (ECG)" variable, resulting in a reduction in specificity. As a result, risk stratification and the disposition of syncope patients remain challenges for emergency physicians. ${ }^{16-18}$

The purpose of this study was to derive a syncope risk scale that would risk-stratify adult ED syncope patients as high (need admission), moderate (need urgent follow-up within 2 weeks), or low (can be discharged with no further follow-up) risk for SAEs within 30 days.

\section{METHODS}

\section{Study design and setting}

We conducted a medical record review of consecutive adult ED patients with syncope at The Ottawa Hospital Civic Campus, an academic adult tertiary care ED. This urban ED has 60,000 patient visits annually and is staffed by emergency physicians certified in emergency medicine by either the Royal College of Physicians and Surgeons of Canada or the College of Family Physicians of Canada. We included patients presenting with syncope over an 18-month period from August 2005 to January 2007. The hospital Research Ethics Board approved the protocol and determined that consent was not required.

\section{Study population}

We identified potentially eligible patient visits within the patient care information system at the Civic Campus of The Ottawa Hospital, which is part of the Canadian National Ambulatory Care Reporting System (NACRS). We used the search terms "syncope," "presyncope," "fainting," "blackout," "loss of consciousness," "fall," "collapse," "seizure," and "lightheadedness" in the chief complaint and primary or secondary discharge diagnosis fields to identify charts for further review. We included patients $\geq 16$ years of age who presented with syncope (defined as sudden transient loss of consciousness with prompt, spontaneous, and complete recovery). We excluded 
patients who were not from the greater Ottawa area, those with a recorded duration of loss of consciousness $>5$ minutes, and those who had a change in mental status from baseline on regaining consciousness, a definite seizure, alcohol- or illicit drug-related loss of consciousness, or head or other significant trauma. The principal investigator (V.T.) assessed the eligibility of screened patients without knowledge of their outcome status. We excluded patients with presyncope because we found it very difficult to retrospectively differentiate presyncope from the symptoms of "dizziness" or "weakness." We used a consecutive sampling method to select potentially eligible records for review. We included both patients who were admitted to the hospital and patients who were discharged from the ED.

\section{Study protocol and data abstraction}

We defined an index visit as the first ED visit during the study period and any additional visit 30 days after the first visit. Any ED visit within 30 days of an index visit was defined as a return visit. We included all patient visits during the study period because the risk of an adverse outcome may vary with each visit. We used patient visits as the unit of analysis.

Variables for investigation were selected based on published literature, a previously conducted systematic review, professional society guidelines, and recommendations by a committee that included two cardiologists with significant syncope research experience, four emergency physicians, and a methodology expert. ${ }^{1,2,17,19,20}$ The principal investigator (V.T.) and a trained research assistant blinded to the patient outcomes collected patient demographics, event characteristics, comorbidities, vital signs, physical examination findings, ambulance ECG strip, ED ECG characteristics, ambulance and ED cardiac monitor abnormalities, results of investigations, and disposition from photocopies of patients' prehospital, nursing, and physician medical records. In the event of a discrepancy between the various documents, the physicians' record was considered accurate. The research assistant abstracted the first $10 \%$ of charts under the direct supervision of the principal investigator. All data that were subsequently abstracted by the research assistant were reviewed by the principal investigator during twice-weekly meetings. In total, we abstracted 105 predictor variables (2 demographic, 5 event characteristics, 11 comorbidities, 1 pre-ED medication, 24 vital signs, 5 clinical examinations, 19 emergency medical services ECG strip and 21 ED ECG/monitor characteristics, 16 investigations, and 1 disposition), comprising 62 categorical and 43 continuous variables (Appendix 1 and Appendix 2). We designed and piloted standardized data abstraction forms prior to the study launch. The form also included the provision to document any unavailable predictor variables. Details of the ECG and cardiac monitoring characteristics abstracted are described elsewhere. ${ }^{21}$

Data were entered into an $S A S$-based data collection interface (SAS Institute, Cary, NC) specifically designed for the study. The interface included built-in range and logic checks, and the accuracy of data collection and entry was monitored through regular reports.

\section{Outcome measures and outcomes assessment}

We defined an SAE as occurrence of any of the following within 30 days of the index visit: death, myocardial infarction, arrhythmia, pulmonary embolism, stroke, subarachnoid hemorrhage, significant bleeding, any procedural intervention to treat a cause of syncope, any condition causing or likely to cause a return ED visit, or hospitalization for a related event (Table 1).

We previously reported that approximately $37 \%$ of SAEs occur between 8 and 30 days after the index visit. ${ }^{13}$ Because it is difficult to arrange follow-up within 7 days in most health care settings in Canada, we chose 30 days as the duration of follow-up for SAEs. We reviewed ED, outpatient clinic, and inpatient admission records from all adult hospitals in the study region to assess for SAE occurrence within 30 days. We also reviewed death records from all adult hospitals in the study region and the provincial coroner's office. We collected both the time and location of occurrence of an SAE. All SAEs were confirmed by two emergency physicians, at least one of whom was blinded to the predictor variables. In cases of disagreement, a third blinded emergency physician adjudicated the outcome. We obtained additional ethics approval from all the local adult hospitals and the provincial coroner's office for this component of the data collection.

\section{Data analysis}

We used $S A S$ version 9.1 for the statistical analysis. We assessed the interobserver agreement for inclusion in the study and selected predictor variables using the 
Table 1. List of serious adverse events and their definitions

a) Death: death from any cause. Confirmation of death within 30 days was done by review of records in all local adult hospitals and records from the provincial coroner's office.

b) Myocardial infarction: defined as an elevation in troponin or electrocardiogram changes consistent with ischemia/infarction and with an accompanying diagnosis of myocardial infarction. It must have been confirmed by the emergency physician or cardiology service or the most responsible physician in the patient's chart.

c) Arrhythmia: specific rhythm abnormality listed below, captured on monitoring thought to have a temporal relationship to the symptom or that required treatment. Rhythm abnormalities include sinus pause $\geq 3$ seconds, symptomatic sinus bradycardia $\leq 35$ beats/min, symptomatic supraventricular tachycardia, atrial fibrillation with slow ventricular response (RR interval $>3$ seconds), Mobitz type II second-degree heart block, complete heart block, symptomatic or sustained $(\geq 30$ seconds) ventricular tachycardia, and pacemaker malfunction.

d) Pulmonary embolism: diagnosis made by ventilation-perfusion (V/Q) scan, computed tomographic scan of the chest, or pulmonary angiogram. If the $\dot{V} / \mathrm{Q}$ scan is very low probability, then the patient is considered not to have suffered an SAE. If the $\dot{V} / \mathrm{Q}$ scan was of low or moderate probability and the patient received or was considered for treatment, then we classified the case as a pulmonary embolism.

e) Stroke: defined by presence of a persistent neurologic deficit with symptoms temporally related to the syncope episode

f) Subarachnoid hemorrhage: confirmed by computed tomography/magnetic resonance imaging of the brain with or without spinal fluid analysis by lumbar puncture

g) Significant hemorrhage: defined as a detected source of bleeding requiring transfusion

h) Any procedural intervention to treat a related cause of syncope: any patient who underwent an acute procedural intervention and would have caused him/her to return if he/she had been discharged was considered to have an SAE. Monitoring of patients, medication changes, and rehydration were not considered to be acute interventions.

i) Any condition causing or likely to cause a return emergency visit: patients with return visits within 30 days of the index syncope visit who were admitted or experienced any of the above outcomes during the return visit were considered to have had an SAE. If the return visit was related but the patients were discharged without admission or the above outcomes, then they were classified as not having suffered an SAE.

j) Hospitalization for a related event within 30 days: defined as hospitalization for syncope or any other related symptom within 30 days of the index syncope visit

$\mathrm{SAE}=$ serious adverse event

Cohen unweighted kappa coefficient. Categorical data were reported as percent frequency of occurrence and continuous variables as means with standard deviations. Univariate analysis (chi-square test with continuity correction or Fisher exact test for nominal variables and unpaired two-tailed $t$-test using separate or pooled variance estimates as appropriate for continuous variables) was used to compare predictor variables among groups with and without SAEs.
Continuous variables identified as significant by univariate analysis were further categorized using the most discriminative cutpoints.

We derived the final model using multivariate logistic regression with stepwise fitting of predictor variables that were significant on univariate analysis $(p<0.05)$. We developed a syncope risk scale by rounding the lowest likelihood ratio $\beta$ coefficients to one and multiplying the other coefficients by the same factor and rounding them to the nearest whole number. ${ }^{22} \mathrm{We}$ evaluated interactions among predictor variables using Mantel-Haenszel and model procedures. We also applied the Hosmer-Lemeshow goodness-of-fit test. ${ }^{23}$

Sample size was determined based on the precision of the sensitivity of the scale to be derived and the bound on the error of the precision estimate (the width of the $95 \%$ confidence interval [CI]). This is a standard technique used in sample size calculation for decision rule studies. ${ }^{24}$ We determined a priori that a sample of 502 patient visits with 50 SAEs would be required.

\section{RESULTS}

During the study period, 915 potentially eligible patient visits were screened and 530 (57.9\%) met inclusion criteria. Twenty-five visits $(2.7 \%)$ could not be included; 13 involved the patient leaving the ED before assessment by the emergency physician, and for 12, treatment records could not be located. Thus, a total of 505 patient visits (55.2\% of those screened) by 490 patients were included in the study.

Table 2 shows the demographic and clinical characteristics, management, and outcomes, including the occurrence and types of SAEs in the study patients. Blood tests were not performed in $11 \%$ of visits, and ECG was not performed in 7\%. The patients who did not have these tests performed differed from those who did in that they were younger (mean age 35 years $\mathrm{v}$. 60 years), healthier (proportion with coronary heart disease $3 \%$ v. $21 \%$ and proportion with arrhythmia $3 \%$ v. $12 \%)$, and more likely to have suffered vasovagal syncope (49\% v. $25 \%)$. There were 49 (9.7\%) SAEs, 27 (5.4\%) of which occurred after ED disposition (either as an inpatient or outside the hospital). The SAEs include five deaths (two in the ED, one as an inpatient, and two outside the hospital).

We evaluated the univariate association between predictor variables and the occurrence of an SAE (Table 3) and found 6 categorical and 11 continuous 


\begin{tabular}{|c|c|}
\hline Characteristic & Patient visits, $n(\%)$ \\
\hline \multicolumn{2}{|l|}{ Demographics } \\
\hline Mean age, yr, (SD) & $58.5(23)$ \\
\hline Female & $254(50.3)$ \\
\hline \multicolumn{2}{|l|}{ Medical history } \\
\hline Congestive heart failure & $30(5.9)$ \\
\hline Coronary artery disease & 99 (19.6) \\
\hline Arrhythmia & $58(11.5)$ \\
\hline Valvular heart disease & $14(2.8)$ \\
\hline Diabetes & 65 (12.9) \\
\hline Hypertension & $174(34.5)$ \\
\hline \multicolumn{2}{|l|}{ Investigations } \\
\hline Bloodwork performed & $448(88.7)$ \\
\hline Electrocardiogram performed & $470(93.1)$ \\
\hline CT of head performed & $123(24.4)$ \\
\hline \multicolumn{2}{|l|}{ Disposition and outcomes } \\
\hline Admitted to hospital & $62(12.3)$ \\
\hline Serious adverse event (SAE) & $49(9.7)$ \\
\hline While in the ED* & $22(4.4)$ \\
\hline After hospital admission* & $17(3.4)$ \\
\hline Outside the hospital* & $10(2.0)$ \\
\hline \multicolumn{2}{|l|}{ Type of SAE (some patients had $>1$ ) } \\
\hline Death & $5(1)$ \\
\hline Arrhythmias & $21(4.2)$ \\
\hline Myocardial infarction & $1(0.2)$ \\
\hline Significant hemorrhage $^{\dagger}$ & $8(16)$ \\
\hline Pulmonary embolism & $4(0.8)$ \\
\hline Stroke & $1(0.2)$ \\
\hline $\begin{array}{l}\text { Conditions likely to cause a return } \\
\text { visit }^{\ddagger}\end{array}$ & $2(0.4)$ \\
\hline Hospitalization for related event & $5(1)$ \\
\hline Procedural interventions done $e^{\S}$ & $31(6.1)$ \\
\hline \multicolumn{2}{|c|}{$\begin{array}{l}\text { CT = computed tomography; ED = emergency department. } \\
\text { *For a list of SAEs, see Table } 3 \text {. } \\
\text { †All significant hemorrhage was due to upper gastrointestinal bleeding. } \\
\text { FIncludes two patients, one with a brain tumour detected in the ED and another with } \\
\text { sepsis detected while the patient was admitted as an inpatient. } \\
\text { "Conditions include pacemaker insertion, gastrointestinal endoscopy with or without } \\
\text { epinephrine injection or laser treatment, chest tube insertion, cardioversion, dialysis for } \\
\text { hyperkalemia, brain biopsy, and thoracoscopic surgery. }\end{array}$} \\
\hline
\end{tabular}

variables that were significantly associated with SAEs. We further analyzed the 11 continuous variables by using various cutoffs and found six variables that met the criteria for multivariate analysis (age $\geq 75$ years, diastolic blood pressure $[\mathrm{BP}]<50 \mathrm{~mm} \mathrm{Hg}$ on arrival, lowest ED systolic BPs $<80 \mathrm{~mm} \mathrm{Hg}$, lowest ED diastolic $\mathrm{BPs}<50 \mathrm{~mm} \mathrm{Hg}$, blood urea nitrogen $[\mathrm{BUN}]>15 \mathrm{mmol} / \mathrm{L}$, and creatinine $>160 \mu \mathrm{mol} / \mathrm{L}$ ).

We performed univariate analysis and recursive partitioning of ED ECG and cardiac monitoring variables to derive the previously published Ottawa Electrocardiographic Criteria (Figure 1). ${ }^{21}$
The interobserver agreements for inclusion into the study and for the two predictor variables (history of shortness of breath and history of congestive heart failure) have also been previously reported. ${ }^{4}$

We conducted multivariate analysis using logistic regression with stepwise selection incorporating the 12 predictor variables that were significant on univariate analysis $(p<0.05)$ and the Ottawa Electrocardiographic Criteria variable. Based on the above-mentioned characteristics of patients with missing predictor variables, we assumed that the condition was absent for categorical variables and the values were normal for continuous variables. The final model with $\beta$ coefficients and odds ratios with $95 \%$ CI for the components is provided in Table 4. It included five clinically important variables: age $\geq 75$ years, shortness of breath, lowest ED systolic $\mathrm{BP}<80 \mathrm{~mm} \mathrm{Hg}$, the presence of the Ottawa Electrocardiographic Criteria, and BUN $>15 \mathrm{mmol} / \mathrm{L}$. There was no evidence of interaction among the covariates, and the model showed good fit (HosmerLemeshow $\chi^{2}$ statistic 0.3852).

Figure 1 shows the derived Syncope Risk Scale, including scores for the five selected variables and risk probabilities based on the value of the final score. The potential total score for patients ranges from 0 to 10 , and based on our findings, patients can be classified as either low (score $=0$ ), moderate (score $=1$ ), or high (score $\geq 1$ ) risk. Figure 2 shows a receiver operating characteristic curve for the Syncope Risk Scale and illustrates an area under the curve of 0.87 (95\% CI 0.84-0.93).

The classification performance of the risk scale for each final score threshold and the expected admission rates if moderate-risk patients were chosen to be admitted versus not admitted is provided in Table 5 . There were no patients in the study with a total score of 9 or 10 . The characteristics of the three patients who fulfilled the moderate-risk criteria with a final score of 1 were two patients who were discharged from the ED after the index visit (one returned with general weakness on the fourth day and was admitted for social reasons, and the second patient returned 30 days later with a subcortical stroke) and a third patient with an ECG showing nonspecific ST-T wave changes who underwent pacemaker insertion for recurrent unexplained syncope.

\section{DISCUSSION}

We developed a scale for risk stratification of ED syncope patients into low, moderate, or high risk for SAEs. 


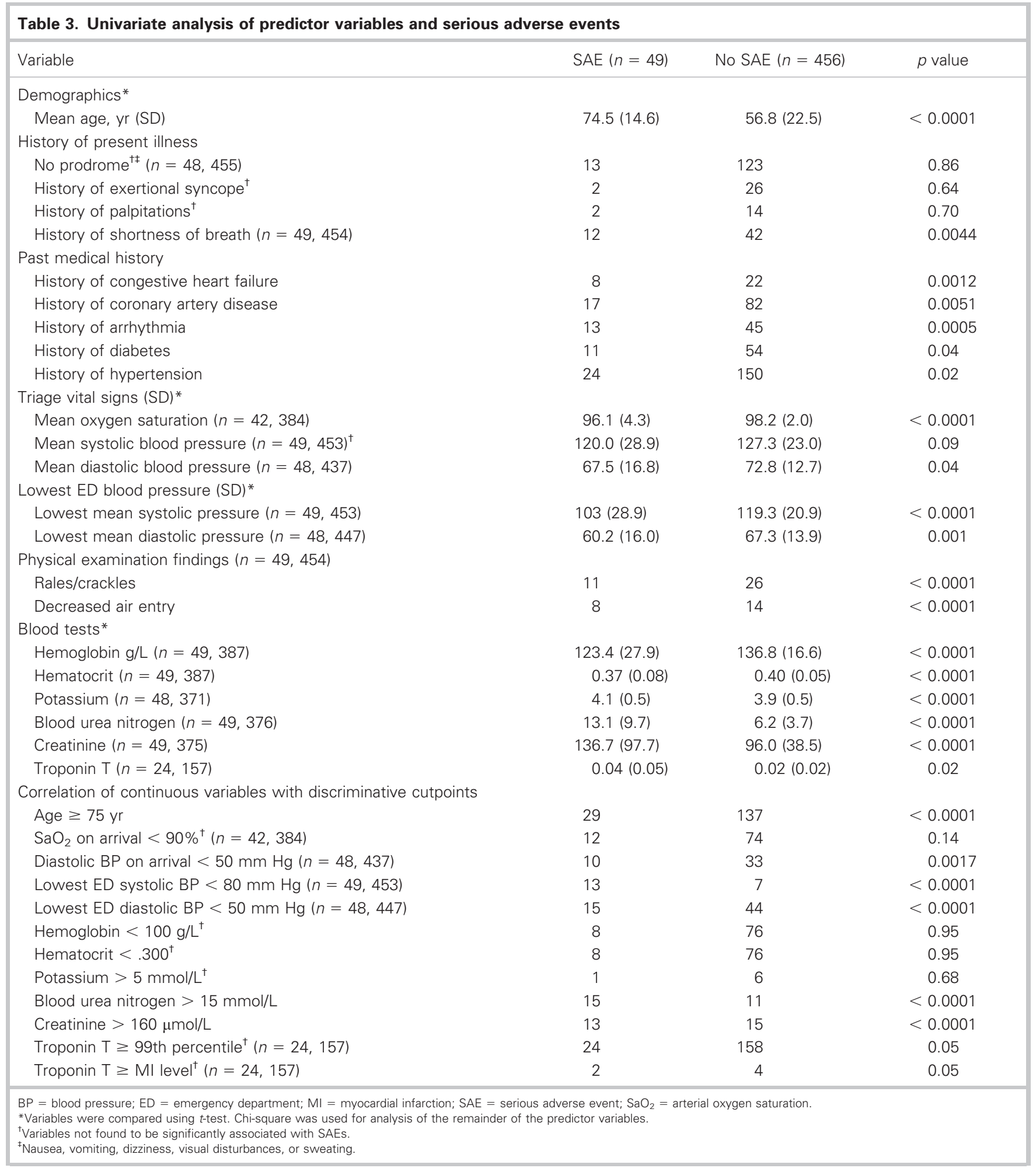

The components of the scale can be easily remembered by the mnemonic BASES (BUN $>15 \mathrm{mmol} / \mathrm{L}$, Age $\geq 75$ years, Shortness of breath, ECG/monitor with Ottawa Electrocardiographic Criteria, lowest emergency department Systolic BP $<80 \mathrm{~mm} \mathrm{Hg}$ ), with 3 points for the blood test, 1 for the age, and 2 for each of the remaining variables. The variables can be easily obtained from syncope patients during their ED assessment, and 
Items

Age $\geq 75$ years

History of shortness of breath

Lowest ED systolic blood pressure $<80 \mathrm{~mm} \mathrm{Hg}$

Ottawa ECG Criteria present on ECG ${ }^{*}$

Blood Urea Nitrogen $>15 \mathrm{mmol} / \mathrm{L}$

Total Score (0-10):

^The Ottawa ECG Criteria includes presence of any of the following on the ED ECG or ED cardiac monitor:

1. Blocks:

a. II degree Mobitz type 2 or III degree atrioventricular block

b. Bundle branch block + 1st degree atrioventricular block

c. Bifascicular block $=$ Right bundle branch + (Left anterior or posterior fascicular block)

2. New ischemic changes

3. Non-sinus rhythm

4. Left axis deviation

5. ED cardiac monitor with sinus pauses, symptomatic arrhythmias or any of the above abnormalities.

\section{Risk of Serious Adverse Events With Syncope Risk Scale Scores}

\begin{tabular}{|c|c|c|}
\hline Total Score & Risk & Category \\
\hline 0 & $0 \%$ & Low \\
\hline 1 & $3.7 \%$ & Moderate \\
\hline 2 & $10.0 \%$ & High \\
\hline 3 & $21.4 \%$ & High \\
\hline 4 & $36.8 \%$ & High \\
\hline 5 & $42.9 \%$ & High \\
\hline 6 & $71.4 \%$ & High \\
\hline 7 & $71.4 \%$ & High \\
\hline 8 & $60.0 \%$ & High \\
\hline
\end{tabular}

Figure 1. The Syncope Risk Scale. ECG = electrocardiographic; $\mathrm{ED}=$ emergency department.

Table 4. Independent predictors of serious adverse events on logistic regression analysis

\begin{tabular}{|c|c|c|c|c|c|c|}
\hline \multirow[b]{2}{*}{ Variable } & \multirow[b]{2}{*}{$\beta$ coefficient } & \multirow[b]{2}{*}{ SE } & \multirow[b]{2}{*}{$p$ value } & \multirow[b]{2}{*}{ Odds ratio } & \multicolumn{2}{|c|}{$95 \% \mathrm{Cl}$} \\
\hline & & & & & Lower & Upper \\
\hline Age $\geq 75 \mathrm{yr}$ & 0.36 & 0.18 & 0.0496 & 2.06 & 1.00 & 4.24 \\
\hline History of shortness of breath & 0.65 & 0.22 & 0.0025 & 3.69 & 1.58 & 8.60 \\
\hline Lowest ED systolic $\mathrm{BP}<80 \mathrm{~mm} \mathrm{Hg}$ & 0.72 & 0.22 & 0.0012 & 4.26 & 1.77 & 10.26 \\
\hline ECG with Ottawa Electrocardiographic Criteria & 0.82 & 0.18 & $<0.0001$ & 5.18 & 2.53 & 10.56 \\
\hline Blood urea nitrogen $>15 \mathrm{mmol} / \mathrm{L}$ & 1.05 & 0.26 & $<0.0001$ & 8.12 & 2.96 & 22.28 \\
\hline Intercept & -0.30 & & & & & \\
\hline Hosmer-Lemeshow goodness of fit & & 0.3852 & & & & \\
\hline
\end{tabular}




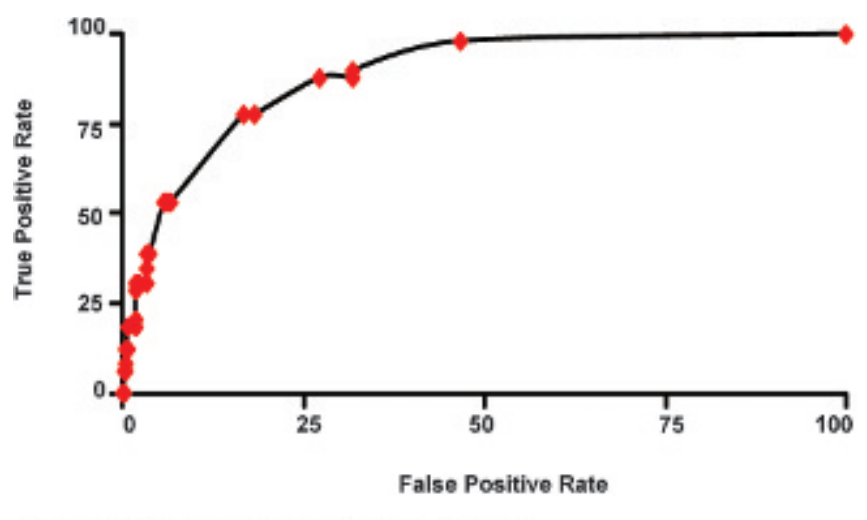

Area under the curve $=0.87(95 \% \mathrm{Cl} 0.84-0.93)$

Figure 2. Receiver operating characteristic curve for the Syncope Risk Scale.

the scale does not require computational aids for final score calculation. The scale showed excellent classification performance, with detection of all SAEs at a projected admission rate that we feel would be acceptable in most countries.

Age has been shown to be an important predictor of SAEs. ${ }^{2,19,25-27}$ Shortness of breath has been found to be an important variable in both our study and the San Francisco Syncope Rule (SFSR) study, and in our study, it was a marker of underlying life-threatening conditions such as pulmonary embolism or massive pleural effusion. We found that patients with systolic $\mathrm{BP}<80 \mathrm{~mm} \mathrm{Hg}$ during the ED stay typically had ongoing gastrointestinal bleeding or sepsis. We found the mean triage systolic $\mathrm{BP}$ variable not to be significant between the groups with and without SAEs but the variable triage systolic $\mathrm{BP}<90 \mathrm{~mm}$ $\mathrm{Hg}$ to be significant on univariate analysis. The variable lowest $\mathrm{ED}$ systolic $\mathrm{BP}<80 \mathrm{~mm} \mathrm{Hg}$ was a better predictor of SAEs than triage systolic BP $<90 \mathrm{~mm} \mathrm{Hg}$. Our study is the first to report the association of serum BUN levels and SAEs in ED syncope patients. One previously reported study found that syncope patients in the setting of chronic bifascicular block and associated renal dysfunction have increased mortality than those without renal dysfunction. ${ }^{28}$ Patients with renal dysfunction may be at higher risk for arrhythmias (either because of uremia or associated electrolyte abnormalities), bleeding, or death (due to comorbidities).

Five previous studies have attempted to develop risk stratification tools to predict short-term SAE risk in adult ED syncope patients. The SFSR study was the first tool to be derived and internally validated but performed poorly on a test of external validation and would significantly increase admission rates if implemented in the Canadian setting. ${ }^{4}$ The Boston Syncope Criteria were a compilation of 25 plausible variables, and the researchers did not apply any multivariate modeling. The criteria are neither practical nor easy to use and have not been externally validated. ${ }^{10}$ The Short-Term Prognosis in Syncope Study found an abnormal ECG, concomitant trauma, absence of prodromal symptoms, and male sex to be associated with SAEs within 10 days. ${ }^{14}$ The classification performance of this tool was not reported, and the tool has not been validated. The Syncope Risk Score was derived to predict SAEs within 30 days in older ( $\geq 60$ years) syncope patients and hence can be applied only to patients $\geq 60$ years old and has not been validated. ${ }^{15}$ The ROSE (Risk Stratification of Syncope in the Emergency Department) rule predicts only 1-month all-cause mortality and requires that serum brain or B-type natriuretic peptide be obtained, a test that is not available in many Canadian EDs. ${ }^{8}$

Our study is the first to incorporate a previously derived abnormal ECG variable into the risk stratification

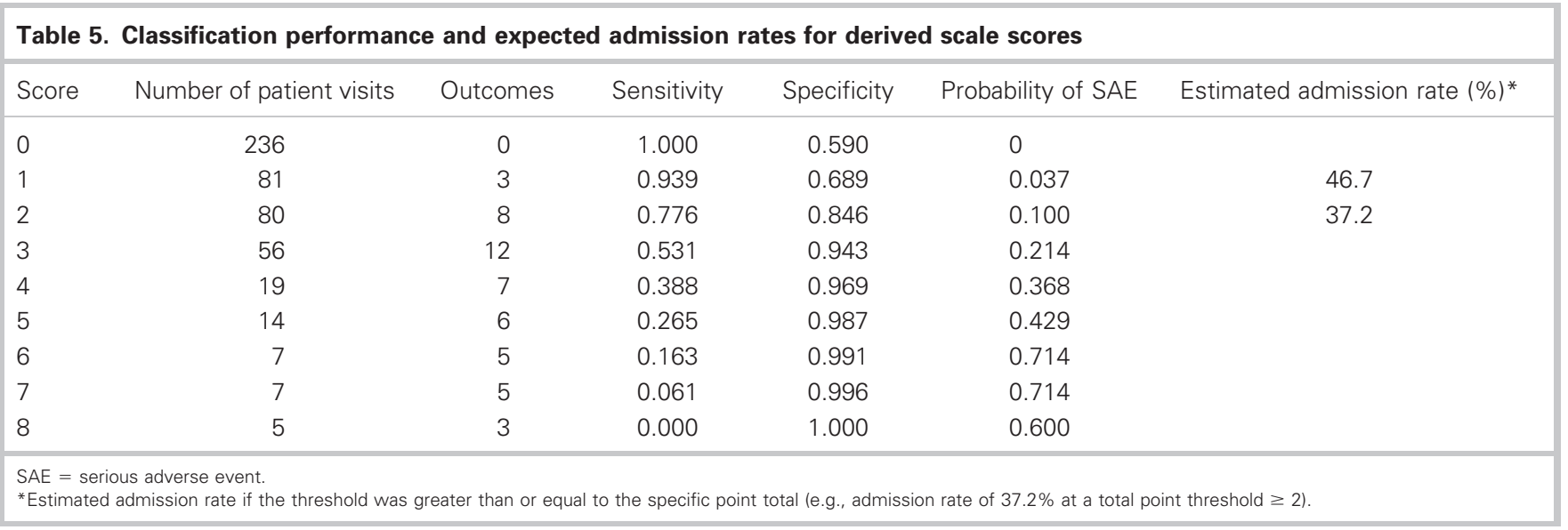


tool. We conducted this study by strictly adhering to previously reported methodological standards for medical records review. ${ }^{29-32} \mathrm{We}$ also conducted the study in keeping with the methodological standards for clinical decision rules. ${ }^{33-35}$

Our study does have potential limitations. As with any study involving medical record review, data may be missing, data could be misinterpreted by extractors, or outcome assessments may be incomplete. We attempted to reduce the risk of bias in patient selection and the abstraction process through adhering to methodological standards for medical record review studies. ${ }^{29-32}$ We only included patients with a local address to maximize outcome assessment and excluded presyncope patients to avoid contamination. Very few patients had important clinical and investigation variables missing, but such patients were low risk for SAEs; hence, we believe it is reasonable for us to assume, when necessary, these variables to be absent or normal. Although we did not assess interobserver reliability for all the extracted variables, we did assess interobserver reliability for the most important variables. Because of the small sample size, there were no patients with a score of 9 or 10, and the risk probability for a score of 8 is lower than that for a score of 7 . The scale requires prospective validation before use in clinical practice.

In our study, $53 \%$ of patients fulfilled the criteria for low risk and suffered no SAEs within 30 days. If validated, this scale has the potential to standardize care of syncope patients, reduce unnecessary admissions, and reduce morbidity and mortality outside the hospital. Validation of this scale will clarify if moderate-risk patients are suitable for urgent outpatient follow-up without the need for hospital admission.

\section{CONCLUSION}

We derived a risk scale that accurately predicts SAEs within 30 days in ED syncope patients. This scale stratifies ED syncope patients as low (can be discharged home), moderate (need urgent follow-up), or high (need admission) risk. If validated, it will be a potentially useful clinical decision tool for emergency physicians, may allow judicious use of health care resources, and may improve patient care and safety.

Acknowledgements: We gratefully acknowledge the Office of the Chief Coroner (Toronto, Ontario), Albert E. Lauwers, MD
(Deputy Coroner), Kona Williams, MD, Sonam Tsomo, RN, Sheryl Domingo, Lilliana Polesello, Cathy Clement, RN, and Angela Marcantonio for their assistance with this study.

Competing interests: This study was funded by a grant from the Department of Emergency Medicine, University of Ottawa. Dr. Thiruganasambandamoorthy receives salary support from the Heart and Stroke Foundation of Canada through the Jump Start Resuscitation Scholarship.

\section{REFERENCES}

1. Moya A, Sutton R, Ammirati F, et al. Guidelines for the diagnosis and management of syncope (version 2009). Eur Heart 7 2009;30:2631-71. [Epub 2009 Aug 27]

2. Quinn JV, Stiell IG, McDermott DA, et al. Derivation of the San Francisco Syncope Rule to predict patients with shortterm serious outcomes. Ann Emerg Med 2004;43:224-32.

3. Quinn J, McDermott D, Stiell I, et al. Prospective validation of the San Francisco Syncope Rule to predict patients with serious outcomes. Ann Emerg Med 2006;47:448-54.

4. Thiruganasambandamoorthy V, Hess EP, Alreesi A, et al. External validation of the San Francisco Syncope Rule in the Canadian setting. Ann Emerg Med 2010;55:464-72.

5. Sun BC, Mangione CM, Merchant G, et al. External validation of the San Francisco Syncope Rule. Ann Emerg Med 2007;49:420-7.

6. Birnbaum A, Esses D, Bijur P, et al. Failure to validate the San Francisco Syncope Rule in an independent emergency department population. Ann Emerg Med 2008;52:151-9.

7. Cosgriff TM, Kelly AM, Kerr D. External validation of the San Francisco Syncope Rule in the Australian context. C7EM 2007;9:157-61.

8. Reed MJ, Newby DE, Coull AJ, et al. The ROSE (Risk Stratification of Syncope in the Emergency Department) study. 7 Am Coll Cardiol 2010;55:713-21.

9. Reed MJ, Newby DE, Coull AJ, et al. The Risk Stratification of Syncope in the Emergency Department (ROSE) pilot study: a comparison of existing syncope guidelines. Emerg Med 7 2007;24:270-5.

10. Grossman SA, Fischer C, Lipsitz LA, et al. Predicting adverse outcomes in syncope. 7 Emerg Med 2007;33:233-9.

11. Quinn J, McDermott D, Kramer N, et al. Death after emergency department visits for syncope: how common and can it be predicted? Ann Emerg Med 2008;51:585-90.

12. Rowe $\mathrm{BH}$, Bond $\mathrm{K}$, Ospina $\mathrm{MB}$, et al. Emergency department overcrowding in canada: what are the issues and what can be done? [Technology overview no 21]. Ottawa: Canadian Agency for Drugs and Technologies in Health; 2006. Available at: http://www.cadth.ca/media/pdf/422_overcrowding_to_e.pdf (accessed July 1, 2013).

13. Thiruganasambandamoorthy V, Hess EP, Turko E, et al. Outcomes in Canadian emergency department syncope patients - are we doing a good job? 7 Emerg Med 2013;44: 321-8.

14. Costantino G, Perego F, Dipaola F, et al. Short- and longterm prognosis of syncope, risk factors, and role of hospital admission: results from the STePS (Short-Term Prognosis of Syncope) study 7 Am Coll Cardiol 2008;51:276-83. 
15. Sun BC, Derose SF, Liang LJ, et al. Predictors of 30-day serious events in older patients with syncope. Ann Emerg Med 2009;54:769-78.e1-5.

16. Graham ID, Stiell IG, McAuley L, et al. Potential areas for new clinical decision rules: comparison of North America and Europe [abstract]. Acad Emerg Med 1999;6:433.

17. Thiruganasambandamoorthy V, Stiell I, Perry J. Systematic qualitative review of clinical decision rules for syncope in ED for predicting adverse outcomes [poster]. CFEM 2007;9:214.

18. Sheldon RS, Morillo CA, Krahn AD, et al. Standardized approaches to the investigation of syncope: Canadian cardiovascular society position paper. Can 7 Cardiol 2011;27:246-53.

19. Colivicchi F, Ammirati F, Melina D, et al. Development and prospective validation of a risk stratification system for patients with syncope in the emergency department: the OESIL risk score. Eur Heart 7 2003;24:811-9.

20. Gregoratos G, Abrams J, Epstein AE, et al. American College of Cardiology/American Heart Association Task Force on Practice Guidelines American College of Cardiology/American Heart Association/North American Society for Pacing and Electrophysiology Committee. ACC/AHA/NASPE 2002 guideline update for implantation of cardiac pacemakers and antiarrhythmia devices: summary article. A report of the American College of Cardiology/American Heart Association Task Force on Practice Guidelines (ACC/AHA/NASPE Committee to Update the 1998 Pacemaker Guidelines). 7 Cardiovasc Electrophysiol 2002;13:1183-99.

21. Thiruganasambandamoorthy $\mathrm{V}$, Hess EP, Turko E, et al. Defining abnormal electrocardiography in adult emergency department syncope patients: the Ottawa Electrocardiographic Criteria. CFEM 2012;14:248-58.

22. Le Gal G, Righini M, Roy PM, et al. Prediction of pulmonary embolism in the emergency department: the revised Geneva score. Ann Intern Med 2006;144:165-71.

23. Hosmer DW, Lemeshow S. Applied logistic regression. Wiley; 2000.
24. Scheaffer RL, Mendenhall W, Ott L. Elementary survey sampling. Duxbury Press; 1979.

25. Sarasin FP, Louis-Simonet M, Carballo D, et al. Prospective evaluation of patients with syncope: a population-based study. Am 7 Med 2001;111:177-84.

26. Martin TP, Hanusa BH, Kapoor WN. Risk stratification of patients with syncope. Ann Emerg Med 1997;29:459-66.

27. Sun BC, Hoffman JR, Mangione CM, Mower WR. Older age predicts short-term, serious events after syncope. $7 \mathrm{Am}$ Geriatr Soc 2007;55:907-12.

28. Marti-Almor J, Cladellas M, Bazan V, et al. Long-term mortality predictors in patients with chronic bifascicular block. Europace 2009;11:1201-7.

29. Gilbert EH, Lowenstein SR, Koziol-McLain J, et al. Chart reviews in emergency medicine research: where are the methods? Ann Emerg Med 1996;27:305-8.

30. Worster A, Bledsoe RD, Cleve P, et al. Reassessing the methods of medical record review studies in emergency medicine research. Ann Emerg Med 2005;45:448-51.

31. Badcock D, Kelly AM, Kerr D, Reade T. The quality of medical record review studies in the international emergency medicine literature. Ann Emerg Med 2005;45:444-7.

32. Lowenstein SR. Medical record reviews in emergency medicine: the blessing and the curse. Ann Emerg Med 2005;45:452-5.

33. Wasson JH, Sox HC, Neff RK, Goldman L. Clinical prediction rules. Applications and methodological standards. N Engl 7 Med 1985;313:793-9.

34. Stiell IG, Wells GA. Methodologic standards for the development of clinical decision rules in emergency medicine. Ann Emerg Med 1999;33:437-47.

35. Laupacis A, Sekar N, Stiell IG. Clinical prediction rules. A review and suggested modifications of methodological standards. FAMA 1997;277:488-94. 


\section{Appendix 1. List of predictor variables abstracted}

Demographics and variables related to the event: age; sex; prodromal symptoms (presence of any symptom including nausea, vomiting, dizziness, pain, hot, cold, cough, urination, visual disturbances, sweating, shortness of breath, palpitations, incontinence or neurologic symptoms [tingling, numbness] prior to loss of consciousness); association with exertion; palpitations at any time; history of paroxysmal nocturnal dyspnea, or orthopnea

Variables from medical history: history of congestive heart failure, coronary artery disease, arrhythmias (atrial or ventricular), cardiomyopathy, valvular heart disease, hypertension, diabetes, cerebrovascular accident, transient ischemic attack or peripheral arterial disease; past syncopal episodes; and medications taken by the patient (diuretics, antiarrhythmics, digoxin, direct vasodilators, nitrates, sublingual nitroglycerine) just before the syncopal episode, $\beta$-blockers, $\alpha$-blockers, combined $\alpha / \beta$-blockers, and calcium channel blockers

Variables from prehospital evaluation/treatment: the first, the last, and the lowest blood pressure readings recorded by emergency medical services personnel; 12-lead ECG characteristics (the same list of characteristics from ED ECG listed in Appendix 2 except QRS and QTc duration); and any ambulance monitor abnormalities - those that are not evident in the 12-lead ECG

Variables from examination: pulse rate, oxygen saturation, respiratory rate, and blood pressure (both systolic and diastolic) at triage and prior to leaving the ED; lowest blood pressure in the serial measurements taken in the ED; postural blood pressure readings-supine, sitting, standing; cardiorespiratory findings (murmur, rales, wheezes, or reduced air entry to the lungs); and evidence of congestive heart failure

Variables from ED ECG: listed in previously published Ottawa Electrocardiographic Criteria study and shown in Appendix 2

Variables from investigations: laboratory values-lowest values of hemoglobin and hematocrit; most extreme values of sodium, potassium, chloride, glucose, calcium, ionized calcium, and magnesium; and highest values of urea, creatinine, creatine kinase, and troponin. New/clinically important abnormalities in the computed tomogram of head, if done (new and clinically important abnormalities were defined as the abnormality detected is the cause of syncope or is a consequence of syncope itself or the fall associated with the syncope; all chronic findings are classified as nonsignificant)

Disposition variables abstracted: data about the disposition of the patient was also collected from the ED record of treatment (i.e., admission or discharge or death in the ED)

$E C G=$ electrcardiogram; $E D=$ emergency department.
Appendix 2. List of specific ECG predictor variables and ED cardiac monitor abnormalities abstracted for deriving the Ottawa Electrocardiographic Criteria from the patients included in the study

a. Rhythm (sinus or nonsinus; if nonsinus specifically, if it is supraventricular tachycardia, multifocal atrial tachycardia, atrial fibrillation or flutter, ventricular tachycardia [sustained or nonsustained], ventricular fibrillation, junctional or idioventricular rhythm)

b. Presence of atrioventricular block and its type if present; paroxysmal atrial contractions or paroxysmal ventricular contractions and their frequencies; presence of intraventricular conduction delay, right bundle branch block, left bundle branch block, or left anterior/posterior fascicular block

c. Presence of left ventricular hypertrophy, right ventricular hypertrophy, left axis deviation, right axis deviation, old myocardial infarction, ST segment and T wave changes consistent with ischemia and if present, whether they are new, secondary ST-T wave changes (defined as ST-T wave changes that are not consistent with ischemia but secondary to causes such as medications, electrolyte imbalances, conduction defects, arrhythmias or pulmonary disease), repolarization abnormalities or nonspecific ST-T wave changes (defined as ST-T wave changes that are not consistent with ischemia or secondary ST-T wave changes)

d. Rate,

e. QRS duration in milliseconds, and

f. Corrected QT interval (QTc) in milliseconds

g. ED cardiac monitor with sinus pauses, symptomatic arrhythmias, or any of the above abnormalities

ECG = electrcardiogram; ED = emergency department. 